\title{
CARBON FIBER POLYMER COMPOSITES
}

doi: 10.2478/cqpi-2019-0037

Date of submission of the article to the Editor: 17/04/2019

Date of acceptance of the article by the Editor: 28/05/2019

Lenka Markovičová ${ }^{-}$orcid id: 0000-0002-1129-5532

Viera Zatkalíková ${ }^{-}$orcid id: 0000-0003-1924-3785

Patrícia Hanusová1 - orcid id: 0000-0002-5732-7990

'University of Žilina, Slovakia

Abstract: Carbon fiber reinforced composite materials offer greater rigidity and strength than any other composites, but are much more expensive than e.g. glass fiber reinforced composite materials. Continuous fibers in polyester give the best properties. The fibers carry mechanical loads, the matrix transfers the loads to the fibers, is ductile and tough, protect the fibers from handling and environmental damage. The working temperature and the processing conditions of the composite depend on the matrix material. Polyesters are the most commonly used matrices because they offer good properties at relatively low cost. The strength of the composite increases along with the fiber-matrix ratio and the fiber orientation parallel to the load direction. The longer the fibers, the more effective the load transfer is. Increasing the thickness of the laminate leads to a reduction in the strength of the composite and the modulus of strength, since the likelihood of the presence of defects increases.

The aim of this research is to analyze the change in the mechanical properties of the polymer composite. The polymer composite consists of carbon fibers and epoxy resin. The change in compressive strength in the longitudinal and transverse directions of the fiber orientation was evaluated. At the same time, the influence of the wet environment on the change of mechanical properties of the composite was evaluated.

Keywords: carbon fibers, polymer matrix, composites, mechanical properties

\section{INTRODUCTION}

The earliest commercial use of carbon fibers is often attributed to Thomas Edison's carbonization of cotton and bamboo fibers for incandescent lamp filaments (ASM Handbook, 2001). However, practical commercial use of carbon fibers for reinforcement applications began in the late 1950s with the pursuit of improved materials for rockets (Bacon and Tang, 1964). Union Carbide marketed a carbonized rayon based fabric in the early 1960s (Bacon and Moses, 1986). DuPont's work with "black Orlon" in the late 1950s showed that acrylics could be thermally stabilized, while Shindo in Japan and Watt et al. in the United Kingdom demonstrated that, by 
using tension through the carbonization process, high mechanical properties could be realized.

In the production of carbon fibers, precursor sources are used, in order of volume, PAN, pitch and artificial silk. Although specific data on the processing of each the precursor is different, all following the base sequence including spinning, stabilization, carbonization, and application; surface treatment or sizing to facilitate handling. Discontinuous carbon fiber whiskers are also now produced in a batch process from hydrocarbon gases using a vapor-liquid-solid growth mechanism (Donnet and Bansal, 1990).

Composites made from carbon fiber are five times stronger than grade steel for structural parts, yet are still five times lighter. In comparison to aluminum, carbon fiber composites are seven times stronger and two times stiffer, yet 1.5 times lighter (Uhríčik, 2016). Carbon fiber composites have fatigue properties superior to all known metals, and, when coupled with the proper resins, carbon fiber composites are one of the most corrosion resistant materials available. Certain mesophase-pitch-based carbon fibers possess thermal conductivity three times greater than copper. The electrical conductivity of PAN and pitch-based carbon fibers is used to dissipate static electricity in a wide variety of computerrelated products. They do not melt or soften with heat, allowing them to be used in such high temperature applications as rocket nozzles and aircraft brakes. In fact, their strength actually increases with temperature in non-oxidizing atmospheres. These unique properties are the result of the fiber microstructure, in both the axial and transverse directions. We can imagine one carbon fiber as a long cylinder with a diameter of approximately $7 \mu \mathrm{m}$. Packed within this cylinder are tiny undulating ribbon-like crystallites which are intertwined and oriented more or less parallel to the axis of the cylinder. The length and straightness of these crystallite "ribbons" determines the modulus of the fiber (D'Abate and Diefendorf, 1985; Singer, 1994; McKee and Memeault, 1981).

\section{EXPERIMENTAL MATERIAL AND METHODS}

Epoxy resins have been successfully used in composite applications since the 1960s. Epoxy resins are a class of thermoset materials used extensively in structural and specialty composite applications because they offer a unique combination of properties that are unattainable with other thermoset resins (Goodman, 1986). Available in a wide variety of physical forms from low-viscosity liquid to high-melting solids, they are amenable to a wide range of processes and applications. Epoxies offer high strength, low shrinkage, the excellent adhesion to various substrates, effective electrical insulation, chemical and solvent resistance, low cost, and low toxicity. They are easily cured without evolution of volatiles or by-products by a broad range of chemical specie. Epoxy resins are also chemically compatible with most substrates and tend to wet surfaces easily, making them especially well suited to composites applications.

Continuous carbon fibers were used in the composites as a reinforcing phase. The carbon fiber feedstock is polyacrylonitrile (PAN). The result of the technological process is carbon fiber with a content of about $85 \%$. Carbon fibers are characterized by excellent tensile strength $2.4-3.1 \mathrm{GPa}$, elastic modulus $200-280 \mathrm{GPa}$ and significant high temperature resistance (in an inert atmosphere, the mechanical properties do not change to $1500^{\circ} \mathrm{C}$ ). 
Composites were prepared by extrusion. The conditions of technological preparation of the composite are the subject of the trade secret of the manufacturing company.

Figure 1 shows the cross-sectional structure of the composite. The carbon fibers have a uniform diameter and the fibers are embedded in the matrix in the direction of flow of the material (epoxy resin). The structure of the composite is highly heterogeneous, and the carbon fibers can also be identified by the naked eye in the resin surface layer.

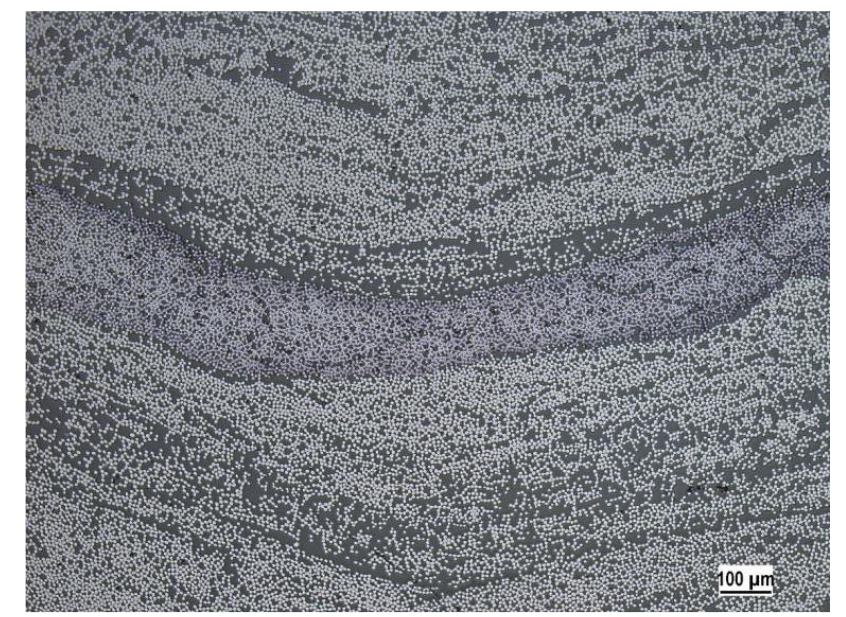

Fig. 1. Microstructure of carbon composite, 100x magnification

The properties of a carbon composite were evaluated by a ShoreD hardness measurement and a compressive strength. The principle of the ShoreD hardness measurement is that the hardness taper is pushed into the surface of the test piece, while the depth of embedding the mandrel into the surface is read directly on the hardness tester in Shore steps. The ShoreD method is designed for hard plastics. The embossed mandrel is sharp, with an angle of $30^{\circ}$ and a very fine peak curvature (radius of curvature of $0.1 \mathrm{~mm}$ ). The test piece has a prescribed minimum thickness of $6 \mathrm{~mm}$ so that the measured hardness is not affected by the substrate hardness. To reduce edge effects, the measurement must not be closer to the edge of the sample than $12 \mathrm{~mm}$. The sample surface must be smooth, flat and free from defects. For better reproducibility of measurement, the standard recommends loading the hardness tester in the center of the tip with a $5 \mathrm{~kg}$ weight. The hardness is measured at five test specimen locations at least $6 \mathrm{~mm}$ apart. The result is an arithmetic mean of all measurements.

During the pressure test, the body is deformed gradually, with the height of the test piece, which may be cylindrical, prism or tube, and the cross section change. For the crushing test, the apparatus was used as a tensile test, using an adapter to change the tensile to pressure force. The test pieces were cylindrical in size: $30 \mathrm{~mm}$ high, $10 \mathrm{~mm}$ diameter. The number of consecutive samples in each direction was 5 .

From the curve, the compressive strength at failure $\sigma_{\mathrm{src}}$ and the corresponding crushing stresses $\varepsilon_{\text {src }}$ is determined:

$$
\begin{aligned}
\sigma_{s r c} & =\frac{F}{A_{0}}[M P a] \\
\varepsilon_{s r c} & =\frac{\Delta h}{h_{0}} .100 \quad[\%]
\end{aligned}
$$


In equations $F$ is force value is, $A_{0}$ is the original cross section of the specimen perpendicular to the direction of action of the compressive force, $h_{1}$ is the original height of the test specimen, $\Delta \mathrm{h}$ is change of height of the specimen.

Part of the samples were exposed to cold distilled water for 24 hours. After the exposure time, the samples were dried to constant weight. After drying the samples, the above mechanical properties were again tested. Changing the monitored parameters is important information about the possibility of using carbon composite products in more demanding applications. With the change of the monitored parameters, the lifetime and functionality of specific products is also related.

\section{RESULTS AND DISCUSSION}

Changes in mechanical properties were compared using specimens before and after exposure to cold distilled water. Table 1 presents the hardness measurement results before and after the 24 hour exposure in water. From the table, it can be seen hardness ShoreD was slightly increasing after exposure to water compared to the unexposed specimens.

Table 1

Hardness of ShoreD carbon composites before and after 24 hour exposure to water

\begin{tabular}{|l|c|}
\hline & ShoreD \\
\hline Before exposure & 76.94 \\
\hline After 24 hour exposure to water & 84.12 \\
\hline
\end{tabular}

According to the authors of R. Selzer and K. Friedrich (1996), carbon fiber composite materials have absorption of about $0.3 \%$. Liquid absorption has been shown by a slight increase in ShoreD hardness values. Table 2 provides the experimental data on pressure test acting to the fiber direction and to the perpendicular direction on fibre.

Table 2

Data from the pressure test before and after exposure to the water (24 hrs.)

\begin{tabular}{|c|c|c|c|c|}
\hline & \multicolumn{2}{|c|}{ Before exposure to water } & \multicolumn{2}{|c|}{ After exposure to water } \\
\hline & $\begin{array}{c}\text { Force acting in } \\
\text { the direction of } \\
\text { the fiber }\end{array}$ & $\begin{array}{c}\text { Force acting } \\
\text { perpendicular } \\
\text { to the fiber }\end{array}$ & $\begin{array}{l}\text { Force acting in } \\
\text { the direction of } \\
\text { the fiber }\end{array}$ & $\begin{array}{l}\text { Force acting } \\
\text { perpendicular } \\
\text { to the fiber }\end{array}$ \\
\hline$\Delta \mathrm{h}[\mathrm{mm}]$ & 0.75 & 0.05 & 1.20 & 0 \\
\hline $\mathrm{F}[\mathrm{kN}]$ & 37.0 & 1.00 & 35.5 & 1.30 \\
\hline$\sigma[\mathrm{MPa}]$ & 335.48 & 8.92 & 211.30 & 11.80 \\
\hline$\varepsilon[\%]$ & 7.98 & 0.53 & 12.57 & 0 \\
\hline
\end{tabular}

The pressure test results represent the change of height and sample width after compression. The values also represent a change in the shape of the sample at the maximum pressure that the samples were able to withstand without breaking. Compressive strength was determined from the measured values. The largest increase in sample height was recorded in the direction of the compressive force parallel to the carbon fibers after exposure to water for 24 hours.

The compressive strength values of the compressive force acting in parallel with the fibers slightly decreased after exposure to the samples in water.

On the contrary, in samples where the compressive force is applied perpendicular to the fibers, we observed a small increase in compressive strength after exposure to water. 


\section{CONCLUSION}

The tested composites represent a resin-carbon fiber system. The properties of the resulting product depend both on the properties of the resin and on the properties of the fiber. Other factors that affect the resulting properties of the system are: environment, size and direction of deformation, ambient temperature, composite manufacturing method, resin to fiber ratio. The results of testing carbon composites are as follows:

- the hardness of the composites increases after 24 hours of exposure in water,

- the best mechanical properties are achieved by the tested composites in the direction of orientation of the carbon fibers in the matrix,

- by exposure to water, decrease in compressive strength occurs in the direction of orientation of the reinforcing fibers. Carbon fibers are characterized by high porosity and a large surface area. Carbon fibers have low surface energy and are therefore more difficult to wet with polymeric binders. The action of water and tension breaks the adhesion at the fiber-matrix interface, accumulates stresses and breaks the composite at lower loads than the composite before exposure to water.

\section{ACKNOWLEDGEMENTS}

The research was supported by Scientific Grant Agency of Ministry of Education, Science and Sport of Slovak Republic and Slovak Academy of Sciences, grant KEGA No. 049ŽU-4/2017 and No. 013ŽU-4/2019.

\section{REFERENCES}

ASM Handbook. Composites, 21, 2001.

Bacon, R., Moses, C.T., 1986. High-Performance Polymers-Their Origin and Development. In: R.B. Seymour and G.S. Kirshenbaum (Ed.), Elseveir, p. 341.

Bacon, R., Tang, M.M., 1964. Carbonization of Cellulose Fibers I. Carbon, 2, p. 211.

D'Abate, G.D., Diefendorf, R.J. 1985. The Effect of Heat on the Structure and Properties of Mesophase PrecursorCarbon Fibers. Proc. of the 17th Biennial Conf. on Carbon, American Carbon Society, p. 390.

Donnet, J.B., Bansal, R.C., 1990. Carbon Fibers. 2nd ed., Marcel Dekker.

Goodman, S.H. 1986. Handbook of Thermoset Plastics, Noyes, pp. 133-182.

McKee, D.W., Memeault, V.J., 1981. Surface Properties of Carbon Fibers. Chemistry and Physics of Carbon, 17, Marcel Dekker, p. 1.

Selzer, R., Friedrich, K., 1996. Mechanical properties and failure behaviour of carbon fibre-reinforced polymer composites under the influence of moisture. Composites Part A, p. 595-604.

Singer, L., 1994. Overview of Carbon Fiber Technology. Material Technology Center Newsletter, Southern Illinois Univ. at Carbondale.

Uhríčik, M., Dresslerová, Z., Palček, P., Oravcová, M., 2016. Temperature dependence of the internal friction of aluminium alloy EN AC 51200. 33 ${ }^{\text {rd }}$ Danubia Adria Symposium on Advances in Experimental Mechanics, pp. 154-155. 